\title{
Vessel wall enhancement by gadolinium-enhanced MRI in a patient with delayed stenosis after mechanical thrombectomy
}

\author{
Takaya Kitano, ${ }^{1,2}$ Shunji Matsubara, ${ }^{3}$ Masaaki Uno, ${ }^{3}$ Yoshiki Yagita ${ }^{1}$
}

\begin{abstract}
'Department of Stroke Medicine, Kawasaki Medical School, Kurashiki, Okayama, Japan ${ }^{2}$ Department of Neurology, Osaka University Graduate School of Medicine, Suita, Osaka, Japan

${ }^{3}$ Department of Neurosurgery, Kawasaki Medical School, Kurashiki, Okayama, Japan
\end{abstract}

\section{Correspondence to}

Dr Takaya Kitano,

takayakitano@neurol.med. osaka-u.ac.jp

Accepted 10 July 2018

\section{DESCRIPTION}

Delayed stenosis of targeted vessels is a reported complication of stent retriever-based mechanical thrombectomy. ${ }^{1}$ We report a case of delayed stenosis with MRI findings that may be related to the underlying stenotic mechanism.

A 46-year-old woman was brought to our hospital with sudden left hemiparesis and unilateral spatial neglect. MRI revealed occlusion of the right middle cerebral artery (MCA) and acute cerebral infarction (figure 1A,B). Emergent mechanical thrombectomy was performed with one stent retriever pass following two aspiration catheter passes, and a red thrombus was retrieved (figure 1C,D). We thought that an embolism had caused the vessel occlusion as no abnormalities were visualised at the occluded site on day 2 (figure 1E). Despite detailed examinations, we could not determine the embolic source during the patient's hospitalisation, so we administered low-dose aspirin. She was discharged on day 46.

Her postdischarge course was uneventful, but follow-up brain MRI 4 months after thrombectomy revealed right MCA near-occlusion without any new ischaemic lesion. Digital subtraction angiography confirmed severe stenosis of the MCA with fine collateral vessels (figure $2 \mathrm{~A}$ ). The stenosis was located in the proximal portion of the MCA's horizontal segment and was just proximal to the initial lesion. She had little atherosclerosis, and thin-slice MRI revealed no mural haematoma. Furthermore, no moyamoya vessels or signs of vasculitis in the vessels other than the right MCA were observed. We therefore concluded that these conditions could not

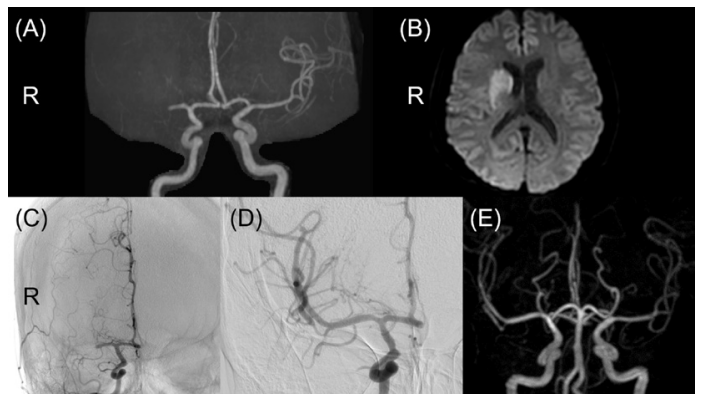

Figure $1 \quad(A, B)$ Initial brain MRI. (C) DSA before mechanical thrombectomy. (D) DSA after one pass with the stent retriever. Significant recanalisation was achieved without sequelae. (E) MRA on day 2. DSA, digital subtraction angiography; MRA, magnetic resonance angiography; $R$, right.

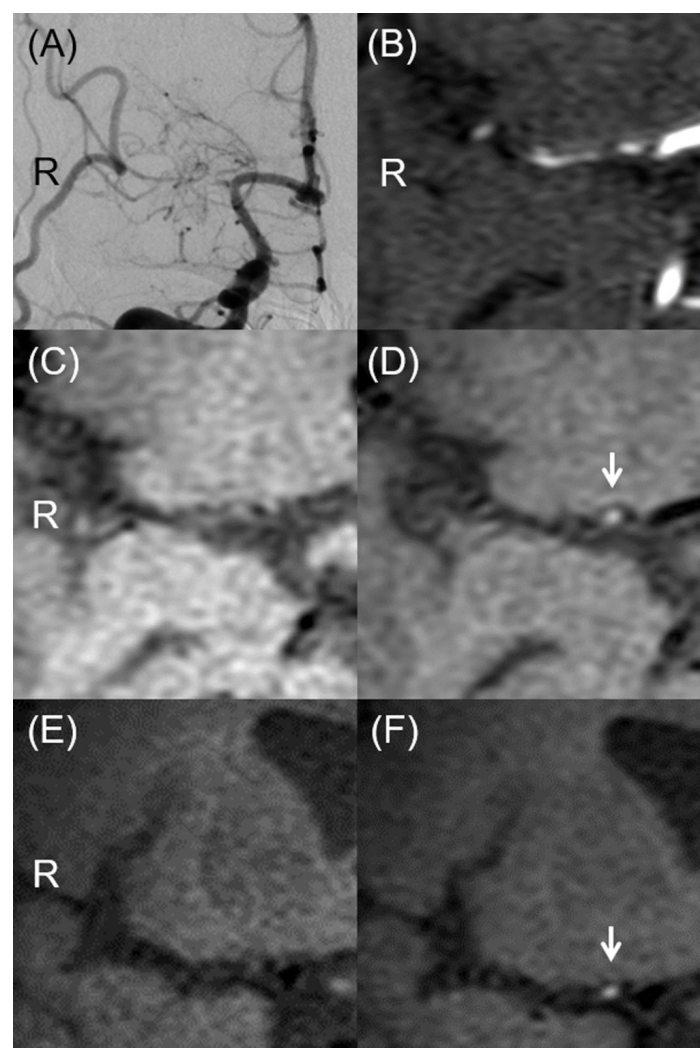

Figure 2 (A) DSA 4 months after thrombectomy. (B) MRA axial view. (C) Axial and (E) coronal vessel wall imaging by 3 Tesla MRI (Philips Medical Systems, Ingenia 3.0T CX Dual, The Netherlands) without enhancement showed no high-intensity signal in the vessel wall. (D) Axial and (F) coronal vessel wall imaging with gadolinium enhancement showed an eccentric highintensity signal (arrows) in the affected vessel wall. DSA, digital subtraction angiography; MRA, magnetic resonance angiography; $R$, right.

explain the stenosis. Gadolinium-enhanced 3 Tesla MRI revealed right MCA vessel wall enhancement (figure 2B-F). The enhanced portion was consistent with the affected artery's stenotic lesion.

Delayed stenosis of the targeted vessel is a potential complication in the chronic phase after thrombectomy. ${ }^{1}$ The severity of delayed stenosis varies. Although our patient was asymptomatic, her stenosis severity was greater than the severities in previously reported cases.

A recent study ${ }^{2}$ reported concentric vessel wall enhancement in gadolinium-enhanced 3 Tesla MRI taken days after mechanical thrombectomy. This 
effect is more common in patients who undergo multiple stent retriever passes and is thought to reflect injury and inflammation of the vessel wall. ${ }^{2}$ Here, we report the first case of delayed stenosis with vessel wall enhancement in the affected portion visualised with gadolinium-enhanced MRI months after mechanical thrombectomy. The temporal evolution of this enhancement remains uncharacterised, but its presence months after thrombectomy presumably reflects protracted postoperative changes. In this patient, the enhancement pattern was not concentric but rather eccentric. It might suggest that the pathological condition was protracted only in a part of the injured vessel wall.

Vessel wall injuries resulting from mechanical thrombectomy have been shown in preclinical studies and autopsies, and rabbit carotid arteries showed thickening of the intima and medial layers 2 weeks after mechanical thrombectomy even in models not involving vessel dissection. ${ }^{3}$ Vessel wall damage by

\section{Learning points}

Delayed stenosis of the targeted vessel is a potential complication in the chronic phase after thrombectomy, and physicians should monitor for this complication during longterm follow-up.

- Vessel wall enhancement by gadolinium-enhanced MRI months after thrombectomy may be related to the pathological condition of the delayed stenosis. mechanical thrombectomy may be relevant to delayed chronic phase stenosis. In our case, the delayed stenotic lesion was just proximal to the initial occlusion site. This discrepancy suggests that the delayed stenosis resulted from vessel wall damage from the mechanical thrombectomy rather than from intimal injuries due to the primary embolism. Our patient's sustained vessel wall enhancement might have been related to the pathological condition of the delayed stenosis.

Contributors TK was responsible for the conception and design of the work, as well as analysis and interpretation. TK, SM, MU and YY were responsible for data collection. TK drafted the article, which was critically revised by SM, MU and YY.

TK, SM, MU and YY were responsible for the final approval of the version to be published.

Funding The authors have not declared a specific grant for this research from any funding agency in the public, commercial or not-for-profit sectors.

Competing interests None declared.

Patient consent Obtained.

Provenance and peer review Not commissioned; externally peer reviewed.

\section{REFERENCES}

1 Kurre W, Pérez MA, Horvath D, et al. Does mechanical thrombectomy in acute embolic stroke have long-term side effects on intracranial vessels? An angiographic follow-up study. Cardiovasc Intervent Radiol 2013;36:629-36.

2 Seo WK, Oh K, Suh SI, et al. Clinical Significance of Wall Changes After Recanalization Therapy in Acute Stroke: High-Resolution Vessel Wall Imaging. Stroke 2017:48:1077-80

3 Arai $\mathrm{D}$, Ishii A, Chihara $\mathrm{H}$, et al. Histological examination of vascular damage caused by stent retriever thrombectomy devices. J Neurointerv Surg 2016;8:992-5.

Copyright 2018 BMJ Publishing Group. All rights reserved. For permission to reuse any of this content visit http://group.bmj.com/group/rights-licensing/permissions.

BMJ Case Report Fellows may re-use this article for personal use and teaching without any further permission.

Become a Fellow of BMJ Case Reports today and you can:

- Submit as many cases as you like

- Enjoy fast sympathetic peer review and rapid publication of accepted articles

- Access all the published articles

- Re-use any of the published material for personal use and teaching without further permission

For information on Institutional Fellowships contact consortiasales@bmjgroup.com

Visit casereports.bmj.com for more articles like this and to become a Fellow 